appeared to be to secure the charcoal-filtering apparatus from being choked up with mud. I constructed a design which I believed would obviate this and other objections, so that the principle might be applied at a moderate cost to any gully under the street level, thus avoiding all obstruction to traffic.-I am, Sirs, yours faithfully,

Feb. 18th, 1899.

ROBERT BARNES, M.D. Lond.

\section{"THE SURGICAL AID SOCIETY AND ITS METHODS."}

To the Editors of THE LANCET.

SIRS,--With reference to Mr. H. Betham Robinson's letter under the above heading in THE LANCET of Feb. 18th will you permit me to say that the letter in question was the first intimation I had had of any dissatisfaction in regard to the case to which he therein alludes, but $I$ am now in correspondence with Mr. Robinson and have no doubt that the explanation of the contingent circumstances will fully satisfy him as to the society's action? In the meantime, may I say for the information of your readers and in answer to the question asked by Mr. Robinson that this society does, as stated in its prospectuses and other publications, accept the certificate of any duly qualified surgeon, and, indeed, a form for that specific purpose is provided at the foot of each letter of recommendation for the benefit of patients who are unable to attend here. It will, however, be evident that this rule, like all others, is liable to exceptions under some special circumstances.-I am, Sirs, yours faithfully,

Richard Tresidder, Secretary.

Salisbury-square, Fleet-street, E.C., Feb. 21st, 1899.

\section{A MEMORIAL TO THE LATE PROFESSOR KANTHACK. \\ To the Editors of THE LANCET.}

SIRs,-The premature death of Dr. Kanthack has been so much felt by his numerous friends that we have received letters from many quarters suggesting the propriety of raising a fund to commemorate his work. It is probably not generally known that, largely on account of his generous expenditure of money in his various researches, he had not been able during the few years in which he was in receipt of an adequate income to provide sufficiently for his widow.

It is therefore proposed to raise a fund the interest of which shall be devoted to the use of Mrs. Kanthack during her life whilst the capital amount can eventually be employed in founding some permanent memorial to the late Dr. Kanthack. All who desire to contribute to the fund are requested to send subscriptions to Dr. Drysdale, 25, Welbečkstreet, London, W.

We remain, Sirs, yours truly,

HENRY T. BUTLIN

AN'THONY A. BOWLBY,

J. H. DRYSDALF,

\section{"REGINA v. REICHARDT"}

To the Editors of THE LANCET.

SIRS,-Once more the vexed question of certification or no certification in early stages of actual or threatened mental alienation has forced itself upon the public attention, and it seems, in view of a forthcoming amendinent of the Lunacy Acts, as if the present were a favourable time to endeavour to settle it once for all upon a practical, common-sense, and definite basis. There are, of course, a considerable proportion of the cases of mental disorder constantly arising in which even from the commencement the morbid manifestations are of so pronounced a character that doubt does not for one moment arise regarding the proper course to be adopted with such cases I do not propose here to deal-they do not come within the scope of the present communication. The Lunacy Act, 1890 , although by no means a perfect Act in every respect, amply and intelligibly provides for dealing with them. It is, however, an altogether different matter when cases presenting less marked or pronounced symptoms occur in private practice. The ordinary medical attendant may well be at a loss to decide exactly what is best to be done to ensure his patients' well-being and safety consistently with the required "non-publicity," usually a first consideration with families under such circumstances. Naturally, however, he proceeds to do all that he considers necessary for his patient: he may even feel obliged to turn the house temporarily into a kind of asylum, and by placing a sufficient number of attendants or nurses at once entirely deprive the patient of his liberty and ensure his safety. Yet under such circumstances I do not think the necessity for certification or notification would be suggested by anyone. But sooner or later a time probably comes when change from home surroundings is considered a necessity and then the conditions become entirely altered, the question not only of deprivation of liberty, more or less complete, but also of pecuniary payment for services rendered to the patient arises, and I think it is worthy of discussion whether from the moment it is decided to remove a patient from home care to the care of others, be they medical or other custodians, for payment that there should arise the necessity of some notification of the fact to a central authority, just as in all cases of admission to asylums public or private and hospitals such notification is required to be made within 24 hours.

In the absence of some such provision no opportunity is given for adequate supervision of the many hundreds of cases scattered throughout the country in unrecognised confinement, and ample opportunity is thus afforded for abuses, against which the Lunacy Acts, however stringently they may be framed, afford no protection.

Feb. 14th, 1899. I am, Sirs, yours faithfully,

\section{THE ACCURACY OF THE MEDICAL REGISTER.}

To the Editors of THE LANCET.

SIRS, - 1 have received a card requesting my interest on behalf of the widow of the late Frederick W. Wilson, M.B. Lond., who died at Blackheath in 1894. This name appears not only in Churchill's Directory for 1899 but in the Meaical Register for 1898 published more than three years after the death of Dr. Wilson. I was under the impression that it was part of the duty of a registrar of deaths to send information to the registrar of the General Medical Council of the death of a medical practitioner registered by him. The name does not appear in the general register of the University of London. Why should it be retained in the Medical Register?-I am, Sirs, yours faithfully,

Feb. 20th, 1899. M.R.C.S., L.S.A.

\section{NOTES FROM INDIA. (From OUR Special OORRespondentr.)}

Examples of Immunity from Plague.-The Progress of the Epidemic.-The Plague Commission.-A Proposed International Sanitary League.-Inoculation for Typhoid Fever.

EUROPEANS have the reputation of a partial immunity from plague. This seems to be borne out not only with regard to liability to infection but also with regard to their better chances of recovery. Quite apart from racial differences two other classes in Bombay have shown a remarkable immunity during the successive epidemics. These are the prostitutes and the street-sweepers. The former are chiefly resident in one of the most crowded quarters of Bombay and they consist of various races and nationalities. In the absence of any register it is impossible to give the precise numbers, but they are placed by those conversant with the district at between 6000 and 7000. Only one case of plague is said to have occurred among them. The medical officers and visiting justices actively engaged in searching for cases of plague found none among this class. These people come from various parts of India, from Bagdad, from Constantinople, from Persia, from Japan, and from Southeastern Europe. It is not very clear to what they owe their apparent immunity. The houses in which they live are described for the most part as clean, well-lighted, and wellventilated, the doors and windows being kept open till the small hours of the morning. This alone, however, is not sufficient to account for the occupants escaping infection, because it is said that in the neighbouring streets as many as 27 bodies of the rictims of the epidemic have been taken out of a few houses in one morning. 